\title{
Prometheus unwound
}

\section{Children of Prometheus: The Accelerating Pace of Human Evolution}

by Christopher Wills

Perseus: 1998.310 pp. $\$ 25$

\section{Adrienne Zihlman}

Books about human evolution tend to fall into two categories: they either emphasize how much like the apes we are in terms of our murderous, hierarchical or sexual behaviour, or they elaborate the contrast between hairy, jungle-bound quadrupeds and our brainy upright selves. Christopher Wills, a molecular researcher, takes the second tack. In his view, we children of Prometheus have stolen fire, language and high technology from the gods of things-as-they-are and have evolved, and we continue to evolve so rapidly that we have left our relatives, the chimpanzees, gorillas and orang-utans, in the Darwinian dust.

Although Wills acknowledges that human and chimpanzee DNA are $98 \%$ identical, he is even more impressed by the degree to which "our big-brained, clever-handed, highly social, language-speaking selves" have outpaced our hirsute relatives in the hominoid Olympiad.

In support of his thesis that the rate of human evolutionary change is accelerating, Wills recounts a number of case studies: how the Tibetans have acquired physiological adaptations to high altitudes; how human haemoglobin variants confer resistance to malaria; and even how one's position in the hierarchy of the British Civil Service affects longevity. He profiles the changing character of Europe, with declining birth rates and rising immigration that will mix gene pools and lead to increased diversity.

Turning from the human present to its past, Wills reviews the latest versions of the human fossil record and concludes that the story of the extinct and presumably less successful Neanderthals represents "the road not taken" by our own species. This judgement may be a trifle premature, as the Neanderthals inhabited Europe and the Middle East for several hundred thousand years and Homo sapiens has been around for no more than 200,000 to date. The extensive morphological differences between Neanderthals and modern humans is barely mentioned, but the DNA comparison reported last year is recounted in entertaining detail.

Examining the earlier fossil record with an eye to 'molecular-clock' timing of the human-chimpanzee divergence to about five million years ago, Wills 'predicts', as others have done, that the earliest hominids will be chimp-like, and in fact australopithecines very much resemble bipedal chimpanzees.
Wills unquestioningly accepts Tim White's claim that his 4.4-million-year-old Ardipithecus ramidus is the earliest-known hominid, although the lack of published evidence for the fossil's bipedality has aroused considerable scepticism in the palaeoanthropological community. Wills does not mention Meave Leakey's more recent discovery in Kenya of Australopithecus anamensis, an undisputed hominid possessing limb bones that demonstrate bipedality four million years ago.

This book, though often interesting and informative, seems to suffer from imprecision in the use of the word 'evolution' and from a lack of coherent focus. It is not always clear whether Wills is referring to genetic, morphological or cultural evolution, as he switches vertiginously from one to another. Sometimes his argument rests entirely at the molecular-genetic level (changes in gene frequencies in populations), and the morphological level is omitted, as in the Neanderthal account. At other times, he abandons quantitative molecular data and builds a hominoid family tree from a motley array of physical and behavioural features, "including the ability to speak, the ability to recognize oneself in a mirror, the ability to walk bipedally, the degree of difference in size between the two halves of the brain, the amount of thumb mobility, the period over which the young are nursed, the amount of skeletal muscle strength, the presence of breast in a nonlactating female, and a number of others".

Wills concedes that chimpanzees are

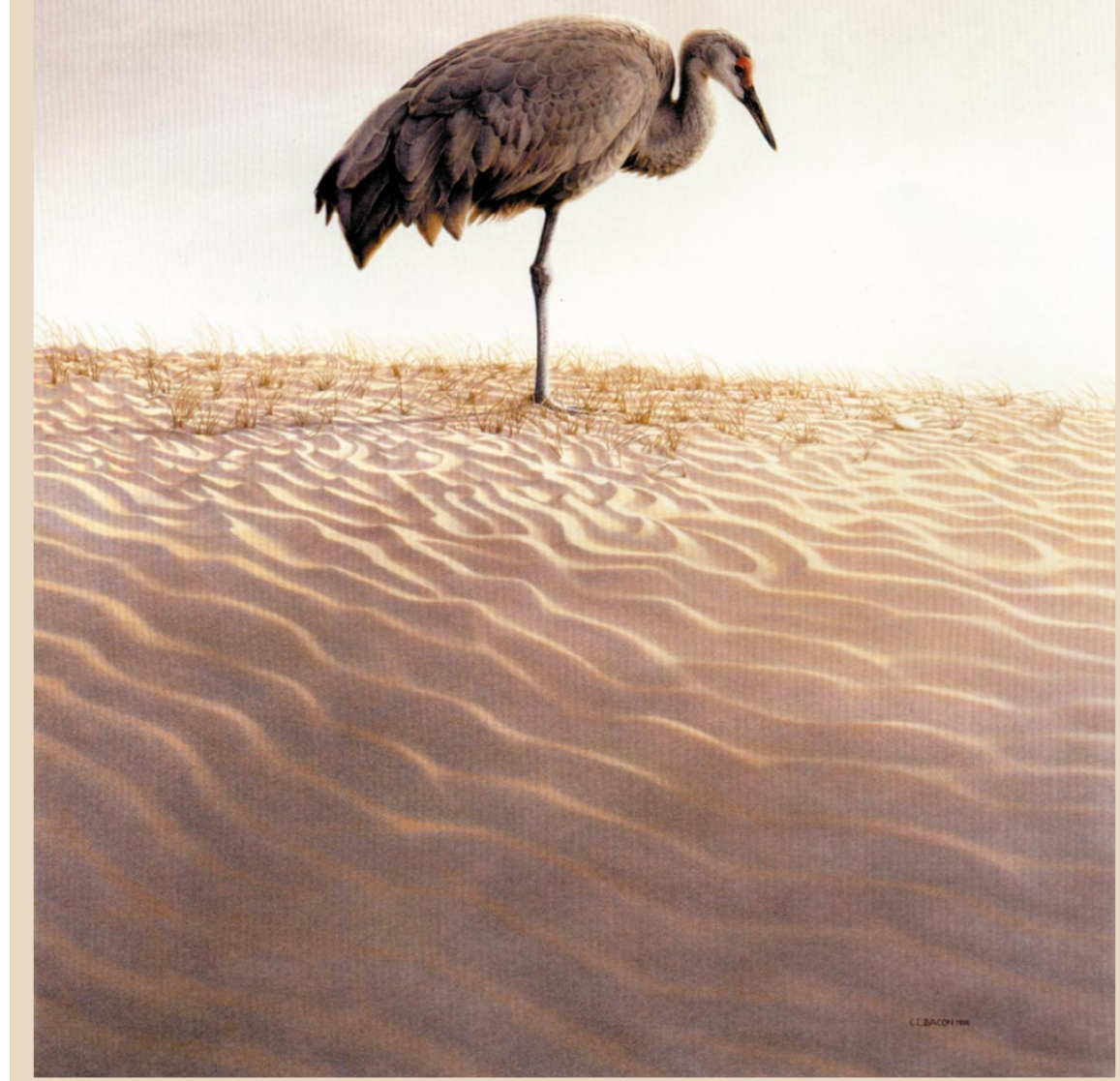

\section{The meaning of wildifie}

Nineteenth-century artists such as Landseer tend to be sentimental or sensational in their representation of animals. The 89 artists whose work is shown in Modern Wildlife Painting by
Nicholas Hammond (Yale University Press, $\$ \mathbf{5 0}$, E35) aim to avoid the anthropocentric. Still, Chris Bacon admits this painting of a sandhill crane symbolizes his own musings about life. 
stronger than humans, but deduces from his anthropocentric items that human evolution has occurred at about 10 times the rate of ape and monkey evolution.

How easy it would be to argue the contrary from the chimpanzee point of view: that we are a most retrograde species who have lost our body hair, facility in climbing trees, female sexual swellings and numerous other primate assets. A more neutral description would merely state that we are adapted to a way of life very different from the ancestral one, and that small changes at the molecular-genetic level can obviously result in major phenotypic and behavioural modifications.

The mystery of the big human brain and what goes on inside it intrigues Wills, as it has fascinated so many others.

The last few chapters, some of the best in this book, deal with the genetic aspects of diseases such as narcolepsy, attention-deficit hyperactivity disorder, schizophrenia, Alzheimer's disease and the much-debated factors in IQ. He speculates that rapid generational changes in microsatellite DNA which are known to account for several neurological diseases, such as Huntington's chorea - could be a mechanism for intellectual improvement. In Wills's opinion, our grandchildren will surely be smarter than us, and within a few generations Einsteins and Mozarts will be commonplace.

These optimistic exegeses, while not without interest, illuminate by omission how little we understand about the molecular, functional and adaptive factors that have

\section{Blast from the past}

This satellite image shows an unusual view of Mount St Helens and the area around it, 11 years after the 1980 eruption. Winds of up to $440 \mathrm{kph}$ flattened a wide area and lava fanned out from the volcano, leaving what is now a horseshoeshaped crater, lower left, containing a lava dome 300 metres high. Faint traces of green in the purple lava show the regrowth of vegetation, especially in protected valleys. It is one of the many dramatic computer-generated digital images, obtained by satellite sensing systems, in America from Space by Thomas B. Allen (Firefly, \$29.95). inflated the human cranium and its contents threefold over the past five million years.

In his last chapter, "Our evolutionary future", Wills unhesitatingly predicts an even bigger-brained advent that will carry us beyond the Solar System to planets of other stars. I admire the courage of someone who can make such projections for a society that cannot predict the next election result or the weather next week.

Are we still evolving? This is the question Wills asks at the beginning and end of his volume, and at many points in between. The answer is, of course, that we are: as are chimpanzees, gorillas, orang-utans, crocodiles and bacteria. Are we really evolving much faster than those other organisms? Not at the molecular level, according to present evidence. Even bacteria, the oldest and most 'primitive' forms of life, show a degree of flexibility in their ability to survive and become resistant to our most potent antibiotics that our own species has yet to prove it can match.

In Darwin's concept of evolution, the direction of evolutionary change is unpredictable, dependent as it is on changing conditions and the vagaries of natural selection. Wills's confidence as to which evolutionary features are good or bad, superior or inferior, faster or slower, conveys perhaps a hint of Promethean hubris.

For the future of the species, let's hope that our grandchildren will, as Wills predicts, be smarter than we are.

Adrienne Zihlman is in the Department of Anthropology, University of California, Santa Cruz, California 95064, USA.

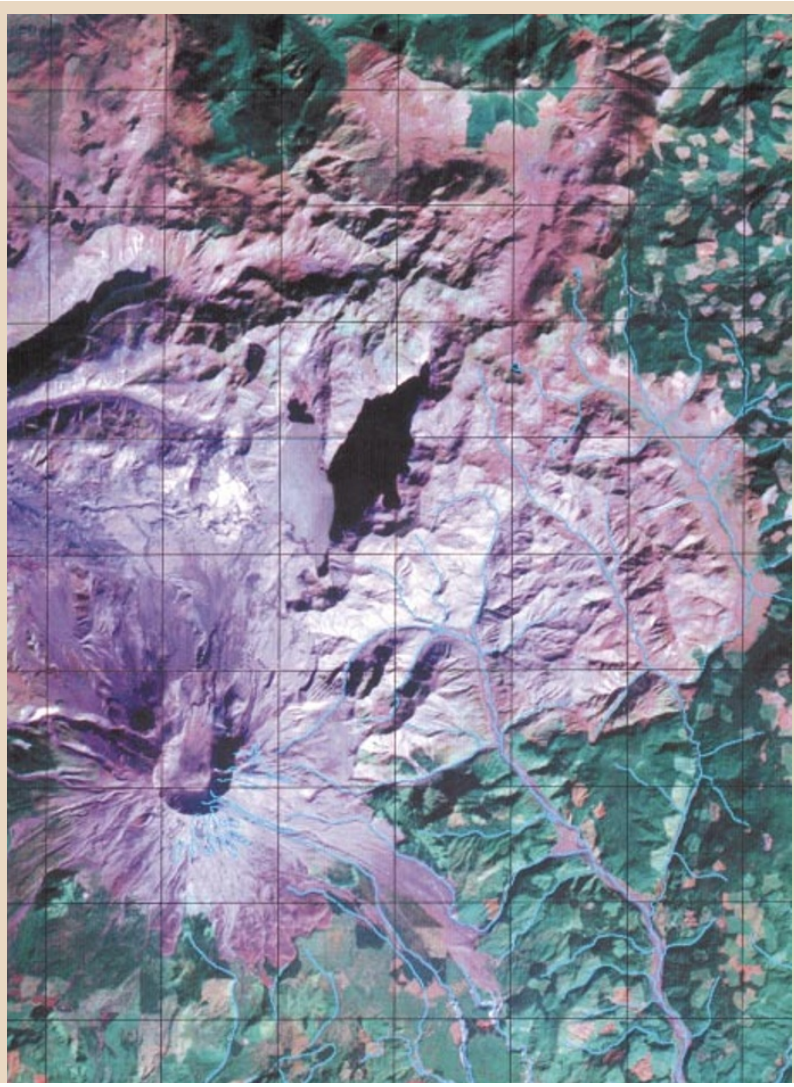

^ ๔ 1999 Macmillan Magazines Ltd
A most uplifting

\section{career}

\section{Out of the Crater: Chronicles of a Volcanologist}

by Richard V. Fisher

Princeton University Press: 1999. 178 pp.

$\$ 24.95, £ 16.95$

\section{Steve Sparks}

The life of an academic field geologist, especially one interested in volcanoes, has considerable attractions. Pleasures to be found include visiting beautiful and sometimes remote parts of the world, and enjoying the companionship of like-minded colleagues, the inevitable adventures and mishaps, and the intellectual challenges of interpreting the tantalizing clues nature provides on how the Earth works. Richard Fisher, professor of geology at the University of California, Santa Barbara, is among the foremost volcanic geologists of the second half of this century. Out of the Crater is essentially his reminiscences.

The book makes interesting and entertaining reading because of the richness of Fisher's experiences and the spectacular nature of his subject. Each short chapter includes anecdotes and descriptions of the parts of the world he has visited, occasional explanations about the science of volcanology and some insights into how he developed his scientific ideas. The reader will be taken to some of the world's great volcanoes - such as El Chichón in Mexico, Vesuvius and Mount St Helens and to diverse cultures: the American West, Argentina and China.

Fisher's unique formative experience was within the context of a remarkable episode in twentieth-century history. In 1946, at 17 years old, he was stationed in the army at Los Alamos and volunteered to go to Bikini atoll, where he observed the atomic bomb tests. His descriptions of the Bikini tests are fascinating, and highlight the military authorities' almost complete lack of understanding of the lethal and long-term effects of radioactivity. To swim in the ocean at Bikini atoll a few days after the test now seems incredible.

What made the Bikini experience so important for Fisher's later scientific achievements was seeing the base surge phenomenon - the cloud of radioactive dust and water droplets that spreads radially along the ground from the base of an atomic explosion. Fisher's significant contribution to volcanological science has been the elucidation of the geology of pyroclastic density currents, a term that encompasses volcanic base surges, pyroclastic flows and volcanic blasts like that of Mount St Helens in 1980.

When volcanic base surges were first recognized, Fisher realized the significance immediately. The enigmatic sedimentary structures in many pyroclastic sequences, 